from the lips of Sir James Graham, or by systematically enticing people to career over the wide world in search of smusement, on the only day in the seren which gives to the majority an opportunity of family converse.

This is not the place for a discussion upon the theological aspects of the Sabbath question ; but, nevertheless, we may be allowed to guard ourselves from misapprehension, by declaring that our convictions are opposed to the puritanical austerities of Sabbath observance. We have adverted to the subject, because there appeared to be imposed upon us the duty of adding our voice to the protest of our medical brethren. With them we feel that the introduction of public amusements on Sunday would be a tremendous stride towards national demoralisation; inasmuch as it would be the commencement of a system which would generate antidomestic influences similar to those which have been produced in France, and which have formed within the Parisian rortex the most dangerous populace in the world -a populace giddy and improvident-governable only by the physical supremacy of an ever present army. If there be any reader who has thoughtlessly admired the glitter and seeming joyousness of a Sunday in Paris, we would ask him to read the bloody chronicles of the guillotine and the barricade; and to ponder well the fact, that one third of the gay crowd by which he had been charmed are destined to die in the hospitals.*

\section{THE IRISH MEDICAL ASSOCIATION.}

IT is with the highest satisfaction that we announce that an Irish Medical Association was formed at Dublin, on the 7th of this month, upon the model of our own institution.

The Branch System has been adopted. And a representative government has been constituted, the executive Council being chosen by the County Branches. The following is the excellent rule to which we refer:-

"4. Council. That the council shall consist of the president, chairman of the council, four vice-presidents, thirtytwo provincial, two general secretaries, and treasurer of the Association, along with sixty-four provincial delegates, two being selected by each County Association annually from its members ; seven to constitute a quorum for the transaction of business. With the council must rest the responsibility of managing and conducting the affairs of the Association from one annual meeting to another; the place and time of their meetings to be arranged by themselves.

The Irish Medical Association holds out to us the hand of fellowship; and let us grasp it right heartily, and bid the sister Association God speed. We have no doubt that, when our laws are revised, the Irish Medical Association will be recognised in the same friendly spirit in which the Provincral Medical ayd Suggical Association is mentioned in the subjoined law.

“10. Ad eundem Members. In order to form a union with our English medical friends, that the members of the Provincial Medical and Surgical Association of England, and so certified by their president and secretary, may be enrolled without the payment of any subscription or fee, ad eundem members of the Irish Medical Association."

It is worthy of notice, that the name originally proposed was the Provincial Medical and Surgical Association of Ireland; but, ultimately, the more catholic and more compact designation, "The Irish Medical Association" has been selected.

* "The Paris Hospitals are the ordinary asylums of the poor when sick. Indeed, one-third of the population of that city die under their rovfs."-DB. HexRY BENAET on Inflammation of the Uterus, p. 44\%. Third Edition, 18j3.

\title{
ORIGITAL COMMUUNCATIOTS.
}

\section{TWO CASES OF SUDDEN DEATH FROM HAMORRHAGE FROM ULCERATION OF THE AORTA.*}

By CHARLES COWDELL, M.D.Lond., Physician to the Dorset County Hospital.

(Read before the Dorset Branch of the Provincial Medical and Surgical Association, on Mfay 31, 1853.)

Case r. George Cockerell, labourer, aged 37, admitted June 27 th, 1852, stated that he had always enjoyed good health until June 1851, when, after a hand day's mowing, he was suddenly seized with rheumatism, from which, however, he thoroughly recorered. He had since been in the hospital at Salisbury, where he was cupped and blistered on his loins, which were then the seat of much pain. On examination when admitted, he was found to be moderately fat, but flabby; and, indeed, in a state of general cachexia. The sound on percussion over the apices of the lungs was good; respiration was tolerably free, with somewhat prolonged expiration; sonorous and sibilant rhonchi were present in both bases posteriorly, and some finer subcrepitant rhonchus in the left base. He complained still of much pain in his loins. He had some cough, with slight expectoration of thick mucus. He had never spat blood. There was slight aortic regurgitation and constriction: no hypertrophy.

The treatment was directed to the bronchitic symptoms. He took with advantage a mixture containing chlorate of potass, compound tincture of camphor, and tincture of squills, with wine of ipecacuanha, and an expectorant pill at bed-time. Under this treatment, his cough and lumbar pains abated; but he was always listless and inactive. In this way he went on for about a month, when he began to expectorate a little blood mixed with the mucous sputa, and it was thought probable that there was latent phthisis, notwithstanding the slight indications of pulmonary disorder. He was accordingly directed to apply leeches to the chest, and to take oleum jecoris aselli. There was no indication of aneurism.

July 27th. When sitting on a bench in the garden this erening, he coughed slightly, was immediately deluged with blood, and died in a few minutes.

Examination of THE Body. The organs in the chest were found tolerably healthy, except the heart and aorta. Slight aortic disease, affecting the sigmoid valves, and diminishing the aortic orifice, was discovered. Patches of incipient atheroma were diffused over the inner surface of the aorta throughout. In the middle of one of these patches of atheroma was an ulcer, extending through the coats of the artery into the right bronchus. There was no dilatation of the artery; but between it and the bronchus there was a very small sac, formed by the outer coat of the vessel.

Case Ir. George Whittle, aged 30, married, a labourer, was admitted at the end of August 1852. He had always enjoyed good health (except an attack of scarlet fever, four or five years previously) until eight weeks before admission, when, after getting wet through while ploughing, he was seized with pain in the left leg, which gradually increased. Of the progressive history of his illness he could gire no account, having, as he said, been too ill to remember anything about it.

When he was admitted, the face was worn and pale; there was great emaciation of the upper extremities. The right shoulder could not be moved without great suffering; indeed, he could with difficulty be carried to his bed, or turned when in it. The legs were cedematous, especially the left; as were also the walls of the abdomen, which pitted under pressure. The heart's apex beat between the

- Reported by W. G. Bacot, Esq. House-Surgeon. The meeting at which this paper was read was held at Bridport, Dorset; S. S. Cory, Esq., President, in the chair. The paper was illustrated with pathological preparations of the diseased parts. 
fourth and fifth ribs, just under the nipple. The sounds at the apex were very indistinct, though a low soft murmur could be caught; at the base, a distinct rubbing to and fro sound was heard. The heart's dulness appeared to extend towards the costo-clavicular articulation. The pulse was 104 , and thready.

In the lungs, percussion was decidedly duller under the left clavicle than under the right. There were strong sibilant and sonorous rhonchi on both sides of the chest; mostly on the right side, where, in the clavicular region, the respiration was loud and blowing, and equal in length to the inspiration. On the left side, the expiration was prolonged, but not nearly as much so as on the right.

Orer the front of the abdomen, there was a rash of a blueish shade, disappearing under pressure; the patches varying in size from that of a fourpenny piece to a pin's head.

The bowels were open; the appetite was good.

The following treatment was followed. A blister was applied over the heart, and the following mixture prescribed:-

\section{B Potnsse nitratis 3 ij. \\ Vini ipecacuanhr $3 \mathrm{ij}$. \\ Spiritûs : $:$ theris nitrosi, \\ 'linct. canpliore compos., äi 亏ेs. \\ Oxymellis scilla $̧ \mathbf{i}$. \\ Aquir ad $3 x>j$. II.}

Sumat cochleuria ij ampla ttâ quâqua horâ.

Septemler 3rd. IIe was much improved, though the legs, especially the left, were much swollen. The urine was moderate in quantity, and deposited phosphates.

IIe gradually improved from this time, so as to be able in two or three weeks to leave his bed, and walk about on crutches, and even to go into the garden to smoke his pipe when the sun shone; but he continued weak and cachectic, with a dejected air and expression.

Oct. tth. Mr. Bacot, the house-surgeon, was called in the evening to see him, and found him sitting on the bedchair (having just passel a motion), complaining of pain in his bowels. By the administration of stimulants at short intervals, he rallied from a state nearly approaching collapse.

October ith. He was this morning quite free from pain, but his pulse was excessively small and weak.

At 2.30 1.x., when visited again, he was found in articulo moitis, and rapidly sank.

Examination of tile Body. Chest. The lungs were covered with recent false memhranc, not uniting them to the costal pleura in front, although it did so behind. There was no tubercle. The lungs were crepitant, and buoyant in water. The pericardium contained a little fluid, and some fine adhesions united the roots of the vessels to the pericardium. The heart was of normal size. There was a large white patch on the anterior surface of the right ventricle, the walls of which were a quarter of an inch thick. The tricuspid valves were healthy; the pulmonary valve had fine reticulations on two of its segments. The wall of the left ventricle was half an inch thick. The aortic valve was thickened and opaque, and had some reticulations. The mitral valve also was thickened at the points of insection of the chordac tendinex; and the opposite portion was puckered and greatly diminished in breadth.

Abclomen. This cavity being opened, a dark plumcoloured fluid escaped, and the intestines on the right of the median line were found to be encased in a coagulum of blood an inch thick. On close examination, the liver was found uniter to the right pillar of the diaphragm. The aorta and vena cava were imbedded in a mass of fibrin, extending from the aortic opening in the diaphragm to just above the iliac arteries. This mass was removed entire, and exposed an aneurismal sac, bounded by the right pillar of the diaphragm, the anterior inferior surface of the liver-the lohulus Spigelii projecting into the sac, and in front hy a layer of thick lymph, together with the vena portre and hepatic artery, which were moreover united by recent lymph to the lower edge of the liver. This cavity was divided into two of unequal size, that attached to the aorta being as large as a walnut, and separated from the larger one by a thick layer of lymph, perfareted with an opening of the size of a goose-quill, and having another opening, by which it communicated with the aorta, as large as a chicken's quill. This last opening was found just above the giving off of the arteries, which usually unite to form the coliac axis, but which in this case arose separately from the aorta. The aorta was roughened by a patch, apparently of atheroma, at this precise spot, without any dilatation, and was elsewhere smooth and healthy. The smaller cavity was rugose, like the lining membrane of the gall-bladder, and contained a tough, tawny coagulum. The larger one-twice the size of the smaller-appeared to be of more recent existence, and to be formed principally by adhesion of the parts and organs whereby it was naturally bounded.

REMakKs. In neither of these cases was the calibre of the aorta at all increased. In both, there was deposit in the inner coat, though very slight, and confined to the immediate neighbourhood of the perforation of the artery in the case of Whittle. In both, the cellular coat appeared to form the ancurismal sac, being dissected away by the infiltration of blood. Both patients were in the state of rheumatic cachexy, contracted under very similar circumstances. But in Whittle there was something more: the valvular heart-affection, and an abscess over the right shoulder-blade (not mentioned in the account of the autopsy).

It appears sufficiently clcar that, in the case of Cockerell, the affection of the artery commenced with his rheumatic attack. The inflammation of the serous lining of the heart (endocarditis) was continued to that of the aorta, ending in atheroma of the ressel; the peculiar characteristics of which-fatty globules and crystalline matterwere distinctly visible under the microscope. Rokitansky affirms that this succeeds to hypertrophy of the lining membrane of the vessel in such cases.

In the case of Whittle, the incrustation in the aorta was so small and thin, that it may be doubted if it was of the same nature as that of Cockerell; and when it is remembered that there were two sacs-the inner one only containing a coagulum, and that, besides the coagulated blood, there was found in the abdomen a quantity of thick plumjuice-like fluid-we retain the impression then felt, that an abscess had given way. The outer and larger sac was probably that of an abscess, which had caused arteritis at the point of contact, with ulceration through its coats, and their dissection of its outer one by the effused blood, thus gradually causing the aneurismal sac. This conclusion is, however, somewhat at variance with the appearance which the larger sac presented, of being more recently formed than the smaller one.

The sudden pain in the belly, and the supervention of syncope $i$ the recumbent posture, indicated internal hæmorrhage from the yielding of arterial coats, either by ulceration or aneurismal rupture. Happily, the cause of death was clearly demonstrated by the post mortem examination, and as clearly exhibited in the well prepared pathological specimens with which the remarks on the case were illustrated.

Dorchester, June 18 8.

\section{SUGAR OF MILK AS AN ARTICLE OF FOOD IN CONSUMPTION AND OTHER PULMONARY DISEASES.}

By JAMFS TURNBCLL, M.D., Physician to the Liverpool Royal Infirmary, and Lecturer on Clinical Medicine to the Medical School.

Those who are familiar with Liebig's works are aware that he established, several years ago, the fact that all the various substances used as food belong to one of two classesthe azotised, or plastic, which form the tissues of the body, 